\title{
Modulating testosterone pathway: a new strategy to tackle male skin aging?
}

\author{
This article was published in the following Dove Press journal: \\ Clinical Interventions in Aging \\ 12 September 2012 \\ Number of times this article has been viewed
}

\author{
Philippe Bernard' \\ Thomas Scior ${ }^{2}$ \\ Quoc Tuan Do' \\ 'Greenpharma SAS, Orléans, France; \\ ${ }^{2}$ Pharmacy Department, Benemerita \\ Universidad Autonoma de Puebla, \\ Puebla, Mexico
}

\begin{abstract}
In men, the level of testosterone decreases with age. At the skin level, the result is observed as a decrease in density and in a lower elasticity. Identifying compounds that are able to increase the level of testosterone appears to be an attractive strategy to develop new antiaging bioactive ingredients for men. Reverse pharmacognosy was successfully applied to identify new natural compounds able to modulate testosterone levels. Among several in silico hits, honokiol was retained as a candidate as it has the greatest potential to become an active ingredient. This result was then validated in vitro on aromatase and 5-alpha-reductase type 1 and 2, which are two types of enzymes implicated in the degradation of free testosterone. Indeed, honokiol was identified as an inhibitor of aromatase, with a half-maximal inhibitory concentration $\left(\mathrm{IC}_{50}\right)$ of about $50 \mu \mathrm{M}$. In addition, honokiol was shown to be an inhibitor of 5-alpha-reductase type 1 , with an $\mathrm{IC}_{50}$ of about $75 \mu \mathrm{M}$. Taken together, these data indicate that honokiol modulates testosterone levels, and its structure has the potential to serve as a lead for future designs of highly selective inhibitors of 5-alpha-reductase type 1 .
\end{abstract}

Keywords: reverse pharmacognosy, honokiol, testosterone, man cosmetics, dermopharmacy

\section{Introduction}

Testosterone plays a key role in the development of male reproductive tissues such as the testes and prostate, as well as promoting secondary sexual characteristics such as increased muscle and bone mass and hair growth. In addition, testosterone is essential for an individual's health and well-being as well as for preventing osteoporosis. A progressive decrease in androgen production such as testosterone is common in aging men and is well documented. ${ }^{1-3}$ The clinical picture of andropause syndrome is characterized by a diminished sexual desire and erectile capability, increased fatigue, depression, skin alterations, as well as by a decrease in intellectual activity, lean body mass, body hair, and bone mineral density that results in osteoporosis. It is also associated with an increase in visceral fat and can lead to obesity. ${ }^{4,5}$

\section{The catabolism of testosterone}

At the age of 30, men's testes produce $95 \%$ of androgen hormones, especially testosterone (about $10 \mathrm{mg}$ a day). About $98 \%$ of all circulating testosterone is inactivated through binding to plasmatic proteins, whereas only the remaining $2 \%$ (called free testosterone) is responsible for all physiological activities of the hormone. Half of the blood plasma protein-bound level is strongly associated with sex hormonebinding globulin (SHBG) while the other half is only weakly bound to albumin. This albumin-coupled testosterone becomes part of the free testosterone. ${ }^{6}$
Correspondence: Philippe Bernard Greenpharma SAS, 3 allée du Titane, 45100 Orléans, France

Tel +33238259980

Fax +33 238259965

Email philippe.bernard@greenpharma.com 
In aging men, estrogen levels rise, resulting in an increase of SHBG and subsequently a global reduction of free testosterone. After the age of 40 years, the capability for SHBG to bind to testosterone augments about $40 \%$, which causes a decrease in libido associated with the symptoms of aging and andropause. ${ }^{7}$ The key control switches for androgen regulation lie in two converting enzymes: (1) either $5 \alpha$-reductase 1 and 2 isoenzymes convert testosterone to dihydrotestosterone (DHT), or (2) testosterone is converted to a lesser extent to $17 \beta$ estradiol by CYP-19 aromatase, a metabolic pathway which is found in both sexes. ${ }^{8}$ The activity inhibition of the aforementioned protein could therefore adjust the level of free testosterone. Particularly, the metabolic pathway modulating the free testosterone level in blood plasma is its biotransformation by $5 \alpha$-reductase enzymes that convert testosterone into DHT. According to many authors, DHT is responsible for prostate hypertrophy, ${ }^{9}$ and also for hereditary and androgen-dependent scalp hair loss (also known as androgenetic alopecia)..$^{10,11}$

Cosmetic skin problems arise with sebogenesis, or acne, which is caused by a combination of endocrinic and bacterial agents leading to skin inflammation. Its androgenic components are male hormones (testosterone and dihydrotestosterone) in addition to specific acne bacteria. ${ }^{12,13}$ The activity inhibition of the aforementioned enzymes should allow for not only the increase of free testosterone levels, but also the reduction of side effects due to its metabolite DHT. That part of testosterone, which was not converted into DHT, is now transformed into estradiol, an active estrogenic metabolite in the presence of CYP-19 aromatase (also called estrogen synthase). ${ }^{8}$ It belongs to the $\mathrm{P} 450$ cytochrome family, which controls the level of estrogens, and the transformation of androgen, androstenedione, and testosterone into estrogens. In men, an elevated level of estrogens may result in serious health problems mostly due to its feminizing effects (eg, gynecomastia). Inhibiting CYP-19 aromatase could reduce the bioconversion of testosterone into estradiol, and consequently it can also reduce the risks associated with high level of estrogens, especially during andropause. ${ }^{14}$

\section{Testosterone and skin}

With aging, a decrease in hormone levels at the skin level modulates epidermal skin moisture, elasticity, and skin thickness. It has been demonstrated that hormone replacement therapy is able to improve these parameters of skin aging in males. ${ }^{15}$
In the field of pharmaceutical technology, several delivery systems have been developed to supply exogenous testosterone. This strategy is not easily applicable for cosmetic applications and presents unacceptable adverse effects such as irritation and contact dermatitis. ${ }^{16}$ Moreover, an increase in testosterone concentrations should also increase DHT levels, the role of which is implicated in hair loss or androgenic alopecia. ${ }^{17}$ For these reasons, the use of testosterone for topical applications, especially in cosmetics, seems quite limited. An alternative would be the discovery of a natural product that is able to increase the testosterone levels only in older males.

Nowadays, androgenetic alopecia (AGA) can be treated by either the oral administration of a selective $5 \alpha$-reductase inhibitor, finasteride, or by topically applying minoxidil, an otherwise known adenosine triphosphate-sensitive potassium channel opener. ${ }^{18}$ A key step is the binding of DHT to the androgen receptor (AR). Follicular cell function depends on various molecular factors: (1) the level of DHT; (2) the presence of active AR; (3) the biotransformation of dehydroepiandrosterone (DHEA) and other weak androgens to more potent androgens such as testosterone or DHT by $5 \alpha$-reductase; (4) the low enzymatic activity of androgeninactivating enzymes. ${ }^{19}$ In a general view, AGA appears to be affected by local pathological modifications of androgen metabolism in skin tissues. Even under physiological conditions, certain differences in androgen sensitivity are observed in the hair follicles from different skin surface sites and vary in accordance to the hairiness of these sites. The concert of metabolic steps involves the enhanced expression of type $25 \alpha$-reductase, while AR with its bound coactivator Hic-5/ ARA55 can upregulate the sensitivity of dermal papilla cells to androgen in AGA. Pathogenic mediators have previously been identified, such as androgen-inducible tumor growth-factor- $\beta 1$ (TGF- $\beta 1$ ), TGF- $\beta 2$, DKK-1, which are androgen-induced suppressors of epithelial follicular cell growth. ${ }^{17-20}$

\section{Honokiol}

Honokiol (Figure 1), or 2-(4-hydroxy-3-prop-2-enyl-phenyl)4-prop-2-enyl-phenol, is a molecular constituent of Magnolia officinalis Rehder et Wilson or Magnolia grandiflora L, a Chinese medicinal plant. Its known pharmacological effects comprise anti-inflammatory, antithrombotic, antiarrhythmic, antioxidative, central depressant, muscle relaxant, and anxiolytic effects. ${ }^{21-23}$ In recent decades, a plethora of research suggested that honokiol possesses anticancer properties with potential implications in cancer treatment. ${ }^{24-28}$ 


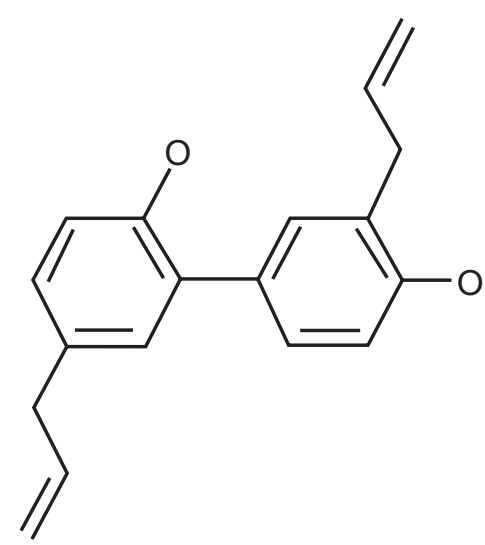

Figure I Structure of honokiol, a hydroxybiphenyl compound.

\section{Reverse pharmacognosy}

Pharmacognosy is the study of the pharmacochemistry of natural raw materials for pharmaceutical, dietary, and cosmetic purposes, but it does not exclusively involve natural materials extracted from plants. ${ }^{29}$ Research in this area can result in the discovery of bioactive molecules after extraction, purification, characterization, and through bioassays.

In some previous publications, we have already introduced and explored the usefulness of a new concept called "reverse pharmacognosy" (RPn) ${ }^{30}$ This concept is similar to "reverse pharmacology," ${ }^{, 31}$ as small molecules are used as probes to evaluate their effects on a biological system, but it differs from reverse pharmacology in its final goal. RPn aims at finding applications for substances of biological origin and their sources (mostly plants). In addition, RPn identifies new biomolecular targets or new biological pathways. It allies chemoinformatic tools and traditional knowledge in search of plants with new applications. The first step is a screening procedure through either in silico or in vitro methods, or even a combination of both, to identify the botanical, pharmaceutical, or cosmetic properties of biomolecules. During the second step, a query into the plant-molecule relational database finds registered plants containing the searched compound. Since RPn is complementary to ordinary pharmacognosy, it requires two or three specific devices: a virtual screening tool such as Selnergy ${ }^{\mathrm{TM}}$ (Greenpharma, Orleans, France), ${ }^{32}$ and/or an in vitro screening platform, as well as a database that provides cross-links between plants and molecules.

In the present study, RPn is applied to find a new modulator of testosterone levels to develop an antiaging formula for male cosmetics.

\section{Materials and methods The Greenpharma database (GPDB)}

GPDB was developed to exploit the steadily growing botanical data, natural chemical structures, and the knowledge obtained from biological tests with vegetal extracts, or isolated molecules, or from scientific literature in general. In addition, it covers phytotaxonomic issues such as the family, genus, and species of organisms, their common names and synonyms, and it also provides information on their applications in traditional medicine (such as the organs targeted in the use of these organisms), as well as indicating the ethnic groups from which the data was collected. GPDB has demonstrated its usefulness in accelerating the discovery of anti-inflammatory compounds. ${ }^{33}$ Currently, the GPDB contains 150,000 molecule and 161,000 organism entries.

In the present work, we focus on this set of natural molecules as input for Selnergy screening on our targets of interest.

\section{In silico screening with Selnergy}

Protein 3D structures were either retrieved directly from published crystal structures at the Protein Data Bank ${ }^{34}$ (PDB; see http://www.rcsb.org/pdb) or built by homology modelling. ${ }^{35}$ The crystal structures of SHBG and aromatase were downloaded from PDB (PDB: 1D2 ${ }^{36}$ and $3 \mathrm{EQM}^{37}$ ). However, in the case of $5 \alpha$-reductase 1 , no crystal structure was available, and its three-dimensional (3D) model was generated by homology modelling. ${ }^{35}$ The accepted assumption for this approach is that two proteins with almost identical and highly phylogenetically related (homologous) amino acid sequences will share similar 3D structures. Hence, the $5 \alpha$-reductase 1 model was safely constructed based on the crystal structure of $5 \beta$-reductase 1 (PDB: $3 \mathrm{CAS}^{38}$ ) thanks to a $40 \%$ sequence homology, in view of a commonly accepted threshold of $25 \%$ to $30 \%$ of the minimal homology required for a length of 80 to 100 residues (typical domain length). Homology modeling was performed with biopolymer and composer modules within the Sybyl 8.0 package (Tripos International, St Louis, MO). ${ }^{39}$ Virtual screening ${ }^{40}$ was conducted with Selnergy. ${ }^{32}$ A candidate was considered to be "accepted" for virtual screening if it fulfilled the following conditions: from a test set of molecules consisting of ligands with known target activities and others that were randomly selected, Selnergy ranks that candidate among the best scoring structures.

An unattended post-processing procedure was performed to discard docking solutions falling outside active site: a spatial fit criterion is taken into account to determine 
whether a ligand was "correctly" docked into the binding cavity. This goal was achieved by comparing the distances between two centroids: one defining the active site of the studied protein and the other defining the docked compound. Each measured the distance from centroid to centroid: $\left(\mathrm{d}_{\mathrm{C}-\mathrm{C}}\right)$, which served as the spatial fit criterion. Any docking position with a $\mathrm{d}_{\mathrm{C}-\mathrm{C}}>4 \AA$ was considered as being "out of the protein active site," and the protein/ligand pair was discarded from further analysis. As Selnergy can propose several poses for the same molecule, the docked pose with the shortest $d_{C-C}$ was selected. A macro was written in Sybyl programming language and implemented to automate this procedure. The Sybyl programming language macro is distributed by Tripos. ${ }^{39}$ Finally, the automated screening and docking processes ended when an expert inspected the outcome based on intuitive grounds in order to discard false-positives ${ }^{40}$ in accordance with the similarities of their binding modes, and with reference to co-crystallized ligands.

\section{Biological assays: aromatase and $5 \alpha$-reductase activity tests}

The aim of the bioassay was to determine the in vitro potency of putative inhibitors - found by our in-silico-screening tool, Selnergy ${ }^{32}$ - of the aromatase enzyme using human placental microsomes as a source of the enzyme, and with titrated water acting as a tracer. ${ }^{41}$ The approved aromatase inhibitor letrozole served as a reference compound.

Furthermore, in the present study the in vitro potency of honokiol as an inhibitor of the $5 \alpha$-reductase isoenzymes type 1 and type 2 was investigated. Transfected human embryonic kidney cells (HEK293), stably expressing the respective isoenzymes 1 or 2 (HEK293-5 $\alpha 1=$ HEK 1 ; HEK293-5 $\alpha 2$ = HEK 2), were used as a whole-cell test system. ${ }^{42}$ On the basis of the enzymatic conversion of the C-labeled substrate androstenedione to the $5 \alpha$-reductase product dihydroandrostenedione, ${ }^{14}$ the inhibitory potency was measured by photo-stimulated luminescence and was compared to those of finasteride, ${ }^{43,44}$ a well-known $5 \alpha$-reductase inhibitor.

\section{Aromatase assay: microsomal aromatase enzyme preparation}

The microsomal fraction was prepared from freshly delivered human term placenta. The tissue was washed in ice-cold $0.15 \mathrm{M} \mathrm{KCl}$ and freed of membranes and blood vessels. The tissue was placed in $0.25 \mathrm{M}$ sucrose $(1.0 \mathrm{~mL} / \mathrm{g}$ tissue $)$ and cut into small pieces with surgical scissors. The tissue was homogenized in an Ultra-Turrax $\mathrm{T} 25^{\circledR}\left(\mathrm{IKA}^{\circledR}\right.$ Works, Inc,
Wilmington, NC) using twenty $10 \mathrm{~s}$ bursts at 20,000 rpm with $50 \mathrm{~s}$ cooling periods. Portions $(50 \mathrm{~mL})$ of the homogenate were subjected to a Kinematica Polytron ultrasonic homogenizer (Labotal Scientific Equipment, Ltd, Abu Gosh, Israel) using five $15 \mathrm{~s}$ bursts at speed 5 with $15 \mathrm{~s}$ cooling periods. The homogenate was centrifuged at 20,000 $\mathrm{g}$ for $50 \mathrm{~min}$ (Hitachi centrifuge; Hitachi Koki Co, Ltd, Tokyo, Japan). The clear supernatant was centrifuged at 148,000 $\mathrm{g}$ for $65 \mathrm{~min}$ (Ultraspin; LKB Instruments, Bromma, Sweden). The pellets were washed in phosphate buffer $(0.05 \mathrm{M} ; \mathrm{pH}$ 7.4) using a Teflon homogenizer. The washed pellets were pooled, dissolved in about $50 \mathrm{~mL}$ of phosphate buffer, and washed twice by centrifugation at $100,000 \mathrm{~g}$ for $60 \mathrm{~min}$. The final pellet was resuspended in $45 \mathrm{~mL}$ of phosphate buffer, and $100 \mu \mathrm{L}$ aliquots were made from a stirring suspension, which was snap frozen and stored at $-70^{\circ} \mathrm{C}$. Protein contents were determined by the method of Lowry et al, ${ }^{45}$ using a SpectraMax Plus384 (Molecular Devices, LLC, Sunnyvale, CA) and bovine serum albumin as a standard.

\section{Aromatase assay: in vitro aromatase inhibition experiment}

Incubations were performed at $37^{\circ} \mathrm{C}$ containing $\left[1 \beta-{ }^{3} \mathrm{H}\right]-$ androstenedione $(250 \mathrm{nM})$, excess NADPH $(0.24 \mathrm{mM})$, $20 \mu \mathrm{g}$ of human placental protein, and phosphate buffer ( $0.05 \mathrm{M} ; \mathrm{pH}$ 7.4). The final volume of the incubation mixture was $1.0 \mathrm{~mL}$. Control incubations were performed without the inhibitor, and the background was determined in an incubation device without any enzymes. The inhibitor was dissolved in $\mathrm{MeOH}$ and serially diluted to reach the three test concentrations of 100,10 , and $1 \mu \mathrm{M}$. Letrozole was tested at $10 \mathrm{nM}$.

The reaction was started by the addition of protein and stopped after $20 \mathrm{~min}$ by the addition of dichloromethane $(10 \mathrm{~mL})$. Following extraction, the tubes were centrifuged at 2,000 $\mathrm{g}$ for $5 \mathrm{~min}$ in a bench top centrifuge. Thereafter, $0.5 \mathrm{~mL}$ of the aqueous phase was removed and placed in a tube to which $1.0 \mathrm{~mL}$ of $5 \%$ charcoal suspension (Norit-activated; Norit Pharmaceuticals, AC Amersfoort, Netherlands) was added. After shaking the tubes for at least $15 \mathrm{~min}$ at room temperature, the tubes were centrifuged at 2,500 $\mathrm{g}$ for $10 \mathrm{~min}$. Two $0.5 \mathrm{~mL}$ aliquots were removed, added to scintillation vials containing $10 \mathrm{~mL}$ scintillation fluid (Quickszint 212; Zinsser Analytic GmbH, Frankfurt, Germany), and were counted in a liquid scintillation counter (1209 RACKBETA, LKB Wallac; LKB Instruments). Counts from the control incubations containing no enzyme were subtracted from each of the incubation counts. 


\section{Aromatase assay: data analysis}

Results were expressed as the percent of inhibition relative to untreated controls. Inhibition rates were calculated out of the mean conversion rates with $(\mathrm{n}=2)$ and without inhibitor $(n=4)$.

\section{$5 \alpha$-reductase assay: cell culture}

HEK 1 and HEK 2 cells were cultivated in Dulbecco's modified Eagle's medium (Invitrogen; Life Technologies Corporation, Carlsbad, CA) (pH 7.4) with $10 \%$ fetal calf serum, penicillin/streptomycin $(100 \mathrm{U} / \mathrm{mL}$ and $100 \mu \mathrm{g} / \mathrm{mL}$, respectively), and $0.5 \mathrm{mg} / \mathrm{mL}$ of Geneticin-418-sulfate. Inhibition assays were performed with HEK 1 and HEK 2 cells seeded at a concentration of $0.25 \times 106$ cells per $1.9 \mathrm{~cm}^{2}$ and were incubated for $20 \mathrm{~h}$ for attachment, doubling, and differentiation in a humidified $5 \% \mathrm{CO}_{2}$ atmosphere at $37^{\circ} \mathrm{C}$.

\section{$5 \alpha$-reductase assay: in vitro inhibition assays}

Test compounds were dissolved in dimethyl sulfoxide (DMSO) and serially diluted in Dulbecco's modified Eagle's medium to reach the three final test concentrations of $100 \mu \mathrm{M}, 10 \mu \mathrm{M}$, and $1 \mu \mathrm{M}$. Incubation mixtures containing $0.24 \mathrm{mM} \mathrm{NADPH}$ and $50 \mathrm{nM}\left[4-{ }^{14} \mathrm{C}\right]$-androstenedione at a final volume of $500 \mu \mathrm{L}$ were pre-incubated at $37^{\circ} \mathrm{C}$ for $10 \mathrm{~min}$. Finasteride used as an internal control was also dissolved in DMSO and diluted to the test concentrations of $100 \mu \mathrm{M}$ and $800 \mu \mathrm{M}$. Controls containing the solvent only ( $1 \%$ DMSO) were treated the same way.

The reaction was started by removing the culture medium and adding the pre-warmed incubation mixture to the cell layers. After $30 \mathrm{~min}$ (HEK 1) or $15 \mathrm{~min}$ (HEK 2), respectively, the reaction was stopped by removing the supernatant. For the extraction of product and nonconverted substrate, $500 \mu \mathrm{L}$ ethyl acetate was added to each sample. After $10 \mathrm{~min}$ shaking, samples were centrifuged for $5 \mathrm{~min}$ for phase separation, and the supernatant was transferred into fresh tubes. After evaporation of the solvent, the dried residues were reconstituted in $25 \mu \mathrm{L}$ of acetone.

The reconstitutes were spotted on a high performance thin-layer-chromatography (HPTLC) plate $(20 \mathrm{~cm} \times 10 \mathrm{~cm}$, Silicagel 60F254 with concentrating zone). The HPTLC plates were run twice in a freshly prepared solution of dichloromethane:diethylether (8:2) as a solvent. Imaging plates were exposed to the HPTLC plates for $48 \mathrm{~h}$. The imaging plates were scanned using a Phosphorimager, and the spots corresponding to $\left[4-{ }^{14} \mathrm{C}\right]$-androstenedione $(\mathrm{A})$ and $\left[4-{ }^{14} \mathrm{C}\right]$-dihydroandrostenedione were integrated using the corresponding software.

\section{$5 \alpha$-reductase assay: data analysis}

Results were displayed as photostimulated luminescence units photo and were corrected for the background. Conversion rates were calculated according to the following formula:

$$
\% \text { conversion }=\frac{\operatorname{PSL}(\mathrm{DHA})}{\mathrm{PSL}(\mathrm{DHA}+\mathrm{A})} \times 100
$$

Inhibition rates, expressed as the percent of inhibition values relative to untreated controls, were calculated out of the mean conversion rates both with $(\mathrm{n}=2)$ and without inhibitor $(n=2)$.

\section{Quality control: acceptability of the assays}

As quality controls, positive control inhibitors were included in the assay set-up. The in vitro assays are considered as acceptable if it meets the following criteria:

- A 50\% inhibition of aromatase by Letrozole at a concentration of $10 \mathrm{nM}$ (tested concentration corresponding to the $\mathrm{IC}_{50}$ of Letrozole).

- A $50 \%$ inhibition of $5 \alpha$-reductase type 1 by Finasteride at a concentration of $800 \mathrm{nM}$ (tested concentration corresponding to the $\mathrm{IC}_{50}$ of Finasteride).

- A $50 \%$ inhibition of $5 \alpha$-reductase type 2 by Finasteride at a concentration of $100 \mathrm{nM}$ (tested concentration corresponding to the $\mathrm{IC}_{50}$ of Finasteride).

\section{Clinical evaluation: patch test study}

Previous to the patch test study, honokiol 1\% and 5\% was evaluated for its irritating potential on the chorio-allantoic membrane of hen eggs and for its mutagenicity potential on the Ames test according to OCDE471. This test evaluates the acute cutaneous tolerance of the raw material and was designed and evaluated by Dermscan (Villeurbanne Cedex, France). A basic cream formula was used including $1 \%$ and $5 \%$ of honokiol. The study was realized during 48 hours using an occlusive method on 20 volunteers with normal skin.

\section{Clinical study: evaluation of the product}

The randomized, double-blind comparative study was carried out in two parallel groups: one group tested the placebo preparation (cream without the active ingredient), and the other group tested the verum product at $1 \%$ (that is placebo $+1 \%$ honokiol). The study protocol was carried out by Dermscan. The study was conducted from October to December. 
The objectives were to evaluate the antiaging and redensifying effects of the tested products.

\section{Volunteers}

The study involved 40 Caucasian healthy men from 55 to 63 years old (mean: $60 \pm 1$ years). The main inclusion criteria were wrinkles, crow's feet around the eyes, and loose skin on the face.

\section{Study protocol}

All volunteers were divided exactly into two groups. The verum group received a cream preparation containing $1 \%$ of honokiol whereas the placebo group received the same formulation without the active ingredient (honokiol). Facial applications (on crow's feet around the eyes) were made twice a day for 2 months. The kinetic data were assessed at three sampling points: day 0, day 28, and day 56. Our assessment criteria were as follows:

- Skin print analysis with the skin image analyzer.

- Dermis density by Dermscan.

- Macrophotographs of crow's feet (for 10 volunteers in each group).

\section{Statistical study}

For statistical analysis, Microsoft Excel 2000 version 9.0 (Microsoft, Redmond, WA) was used. The statistical method used was the Student's paired $t$-test.

\section{Results}

\section{Molecular modeling: virtual screening results from Selnergy}

Testosterone level is controlled by numerous enzymes, receptors, and carrier proteins. After consulting the underlying metabolic pathways for testosterone in the Kyoto Encyclopedia of Genes and Genomes database (Kanehisa Laboratories, Kyoto, Japan) ${ }^{46}$ we inspected three enzymes for their relevant biological properties. The rationale to select the target structures in terms of molecular modeling is the following:

- The protein must occupy a key position in the regulation system of maintaining testosterone levels.

- The inhibition of the protein reflects the desired biological properties because it is usually easier to find inhibitors for enzymes or receptors than exogenous activators.

- Sufficient structural data exists to conduct virtual screening studies.

We found that aromatase or cytochrome P450 19A $1^{47}$ $5 \alpha$-reductase type $1^{48}$ and $\mathrm{SHBG}^{49}$ were amenable to further scrutiny.
$3 \mathrm{D}$ protein models were generated for their posterior use as target structures in in silico calculations with Selnergy. Our software allows for the simultaneous virtual screening on all three targets in order to detect putative selectivity and/ or synergy. Approximately 150,000 natural compounds were filtered in the GPDB database. Each of the 150,000 molecules was ranked by Selnergy according to its computed interaction energies with each of the three targets. The top $1 \%$ of all docked poses in terms of estimated binding energy was post-processed with the aforementioned procedure to retain only those molecules from successful docking. Table 1 lists the hand-selected compounds after final inspection. Three compounds were judged as being the most promising. Toxicity concerns, procurement, and intellectual property issues were then documented and evaluated for all three molecules. Two molecules were henceforth discarded, leaving only one molecule as the best candidate: honokiol. This is the only molecule that exhibited a putative activity on all selected targets, and thus it ranked as the best molecule. Honokiol appears to act on two pathways, and its inhibition leads to the increase in the rate of testosterone production. The second hit that appeared in the database was phloretin, but it was abandoned due to its limitation of exploitation in cosmetics: its antiaging property is claimed in several patents though the mode of action is still unclear. The third molecule, (S)-3,5-Diiodothyronine, was also excluded due to possible hormonal issues.

Selnergy results are illustrated in Figure 2, where honokiol is docked into the aromatase active site. We can observe the complementarities in shape and in electrostatic properties (hydrophathy). Note that one of the ethylene groups is closed to the ferric central ion of the heme group and may interact with the cation.

If these predictions are confirmed by experiments, honokiol will be a good candidate for an active ingredient in antiaging skin care. Furthermore, it can be found in Magnolia spp. which is already used in cosmetics in other applications. This is another reason why we selected honokiol for further experimental investigation.

\section{Biological activities: aromatase and $5 \alpha$-reductase assays}

\section{Aromatase assay}

Honokiol's potential aromatase inhibition was tested during in vitro experiments at three concentration levels of $100 \mu \mathrm{M}$, $10 \mu \mathrm{M}$, and $1 \mu \mathrm{M}(\mathrm{n}=2)$. Their results are displayed in Table 2 and are expressed as the percentage of inhibition. Letrozole, a 1,2,4-triazole derivative, served as a positive 
Table I Final selection of putative molecules targeting testosterone pathways

\begin{tabular}{l}
\hline Molecules \\
\hline Honokiol
\end{tabular}

Abbreviations: CAS, Chemical Abstract Service index number; SHBG, sex hormone-binding globulin.

control and was tested at a concentration corresponding to its $\mathrm{IC}_{50}$ value $(10 \mathrm{nM})$ in the same test system.

Honokiol displayed a concentration-dependent inhibition of the aromatase enzyme reaction, indicating a competitive binding of the test item towards the active site of the enzyme. The $\mathrm{IC}_{50}$ value of the test item is assumed to be in the range between 40 to $60 \mu \mathrm{M}$. In stark contrast, the $\mathrm{IC}_{50}$ value of Letrozole, which was determined to be within a

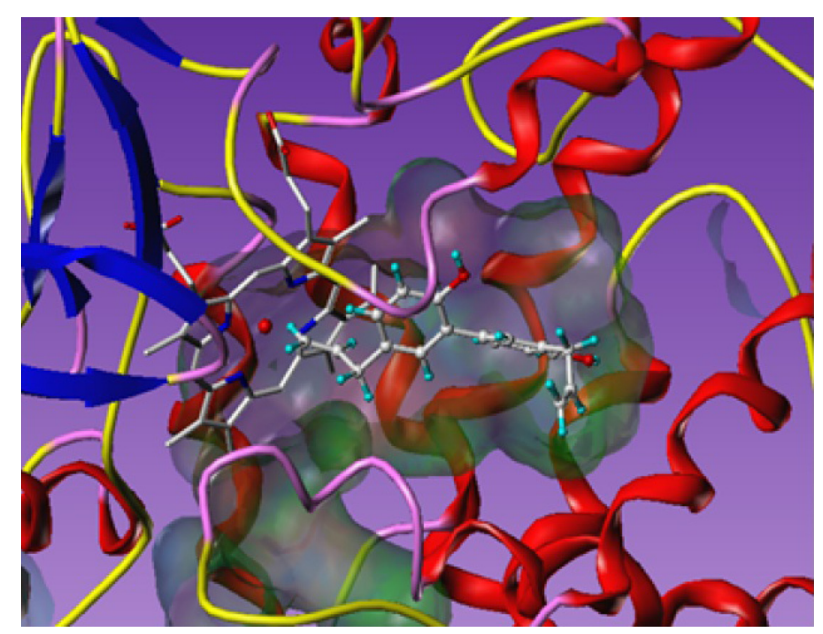

Figure 2 Honokiol (displayed in balls and sticks style) docked into the aromatase active site.

Notes: The backbone of the enzyme is represented as ribbons with red colors for helices, blue arrows for beta-sheets. Rose and yellow segments represent turns and loops, respectively. The heme with the ferric central atom (red sphere) is displays as capped sticks. The active site is modeled with a transparent surface; hydrophobic areas appear in brown, while hydrophilic and intermediate zones show blue and green colors, respectively. Carbon atoms are colored in white, nitrogen in blue, oxygen in red, and hydrogen in cyan. range between 7 to $10 \mathrm{nM}$, is more than three orders of magnitude lower than the estimated $\mathrm{IC}_{50}$ of the test item. Nevertheless, we should bear in mind that honokiol is a natural lead compound without any chemical optimization.

\section{$5 \alpha$-reductase assay}

The test item, honokiol, was tested in vitro for the inhibitory potential towards $5 \alpha$-reductase type 1 and type 2 in a cell-based assay using stably transfected HEK293 cells at $100 \mu \mathrm{M}, 10 \mu \mathrm{M}$, and $1 \mu \mathrm{M}$.

The dual $5 \alpha$-reductase inhibitor finasteride - an azaandrostene derivative - was tested as a positive control at concentrations of $800 \mathrm{nM}$ and $100 \mathrm{nM}$, corresponding to the $\mathrm{IC}_{50}$ values of finasteride for $5 \alpha$-reductase type 1 and $5 \alpha$-reductase type 2 , respectively. The results of this study are presented in Table 3.

Honokiol inhibited $5 \alpha$-reductase isoform type 1 in a concentration-dependent manner. A competitive binding of the test item towards the active site of the enzyme is assumed. The $\mathrm{IC}_{50}$ value of the test item for isoform 1 is estimated to be in the range of $60-90 \mu \mathrm{M}$. In contrast, honokiol did not display any affinity towards $5 \alpha$-reductase isoform type 2 .

Table 2 Inhibition of aromatase in vitro by honokiol and letrozole

\begin{tabular}{lll}
\hline Compound & Concentration & \% inhibition aromatase \\
\hline Honokiol & $\mathrm{I} \mu \mathrm{M}$ & 0 \\
& $10 \mu \mathrm{M}$ & 13 \\
& $100 \mu \mathrm{M}$ & 88 \\
Letrozole & $10 \mathrm{nM}$ & 61 \\
\hline
\end{tabular}


Table 3 Inhibition of $5 \alpha$-reductase in vitro by honokiol and finasteride

\begin{tabular}{llll}
\hline Compound & Concentration & \% inhibition $\mathbf{5} \alpha$-reductase type I & \% inhibition $\mathbf{5} \alpha$-reductase type $\mathbf{2}$ \\
\hline Honokiol & $\mathrm{I} \mu \mathrm{M}$ & $\mathrm{I}$ & $\mathrm{NI}$ \\
& $10 \mu \mathrm{M}$ & $\mathrm{II}$ & $\mathrm{NI}$ \\
& $100 \mu \mathrm{M}$ & 64 & $\mathrm{NI}$ \\
Finasteride & $100 \mathrm{nM}$ & $\mathrm{II}$ & 85 \\
& $800 \mathrm{nM}$ & 48 & 89 \\
\hline
\end{tabular}

Abbreviation: $\mathrm{NI}$, no inhibition.

In comparison, the $\mathrm{IC}_{50}$ values of Finasteride for $5 \alpha$-reductase inhibition were found in the range of $800 \mathrm{nM}$ for isoform type 1 and $100 \mathrm{nM}$ for isoform type 2 . In this system, Finasteride is a 100 -fold more potent inhibitor of $5 \alpha$-reductase type 1 than honokiol, which is a natural compound without any prior chemical optimization.

Due to the fact that the test item, honokiol, did not affect $5 \alpha$-reductase type 2 , this compound may be considered to be a new lead for a selective $5 \alpha$-reductase type 1 inhibitor since this is the first time that a biphenolic scaffold is reported to be selectively active on $5 \alpha$-reductase type 1 .

\section{Clinical results: patch test study}

Prior to patch test studies, we verified that honokiol has no mutagenic and no irritation effects under Ames and chorio-allantoic membrane of hen egg assays. Under the patch test study conditions - 48-hours with an occlusive method on 20 volunteers with normal skin - the $1 \%$ skin preparations remained nonirritating after 30-minute and 24-hour readings. At a 5\% level, three volunteers recorded skin irritations and testing was immediately abandoned. The 1\% preparations, however, are well tolerated without safety concerns and therefore constitute the highest levels of honokiol in use for all our clinical studies.

\section{Clinical results: clinical study of antiwrinkle effect}

The preparation without the active ingredient induced no statistically significant variation of the cutaneous relief parameters after 28 or 56 days of administration. After the 56 day period, $71 \%$ of all volunteers presented a reduced count of typical wrinkles $(-8 \%)$. After the first 28 days of using the $1 \%$ honokiol treatment, the number of micro-relief furrows $(-13 \%)$ and the number of average wrinkles $(-3 \%)$ slightly decreased in $69 \%$ of the volunteers. Then, after the 56-day treatment, the print analyses showed a fairly reduced number of deep wrinkles $(-11 \%)$. These results reflect both antiwrinkle and smoothing effects (Figures 3A and 3B) with statistical certainty $(P=0.058)$ that is nearly significant at a $P$ level of $P<0.05$.
The control product (placebo without the active ingredient) induced no significant variation of the dermis density after 56 days of skin treatment. The verum product containing $1 \%$ of honokiol, however, induced an increase of the dermis density after 56 days in $60 \%$ of all volunteers. On average, an increase of the dermis density of $+5 \%$ was clearly observed (Figure 4).

\section{Discussion}

Our present combined approach with in silico screening and clinical testing extends the scientific literature attesting to the role of honokiol's dermopharmaceutical modulation capacity in the field of antiaging treatment for male skin. This is based on new evidence gained from our randomized, double-blind comparative study to observe the dermatological effects of honokiol among male volunteers. Firstly, the placebo administration did not show any antiwrinkle or densifying effect. Secondly, the verum preparation containing a modulator of testosterone such as $1 \%$ honokiol showed a smoothing and an antiwrinkle effect as well as a densifying effect. It was demonstrated by other authors that honokiol is an antioxidant and myo-relaxant. ${ }^{21-23}$ These properties may exert antiwrinkle effects. However, the increase of skin density cannot be entirely explained by these properties and may be attributed to the property of honokiol that modulates the testosterone pathway disclosed herein. In view of our preliminary findings, additional clinical studies will be necessary to consolidate this postulate: increasing the testosterone production rate in skin of males may be beneficial for antiaging; this concept needs to be explored in further detail.

According to the common literature sources in the life sciences, little original research has focused on the cosmetically relevant connection between testosterone and skin-aging in male adults. Our study tries to fill in the gap, taking the testosterone antiaging assumption as the starting point for our working hypothesis. In contrast, the relation between endocrine activity deficiencies and certain age-associated diseases like the andropause (lack of testosterone) has found its way into clinical studies. Intriguingly, attempts to reverse clinical manifestations 
A
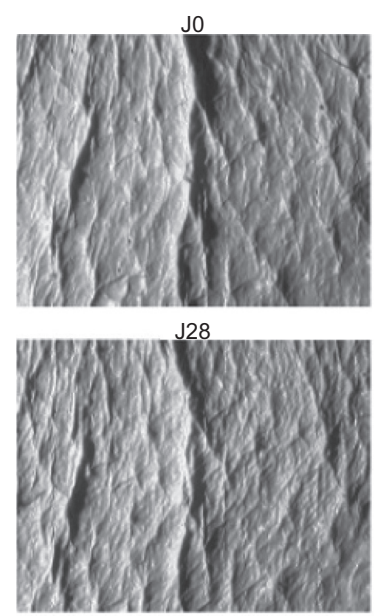

J56

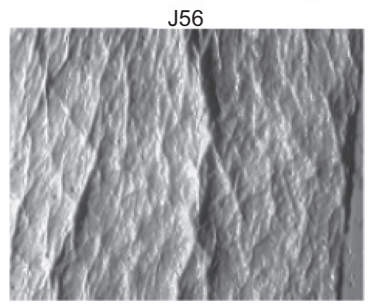

Volunteer \#9

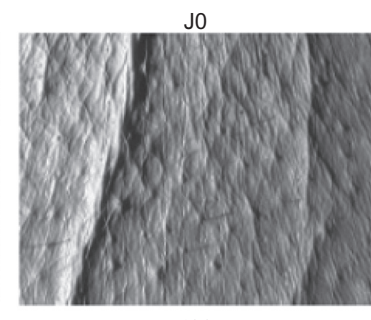

$\mathrm{J} 28$

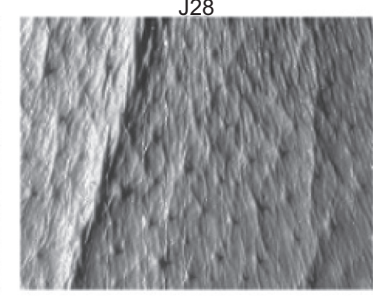

J56

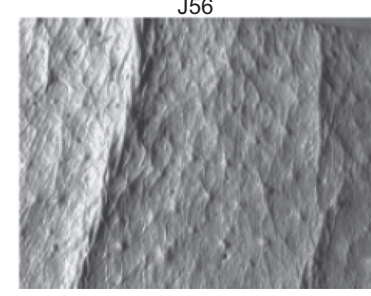

Volunteer \#17

Figure 3A Antiwrinkle effect of a cream containing I\% of honokiol.

Note: Observations taken for two typical volunteers (number 9 to the left, and number 17 to the right) at start (day 0 ), halfway (day 28 ), and study end (day 56 ).
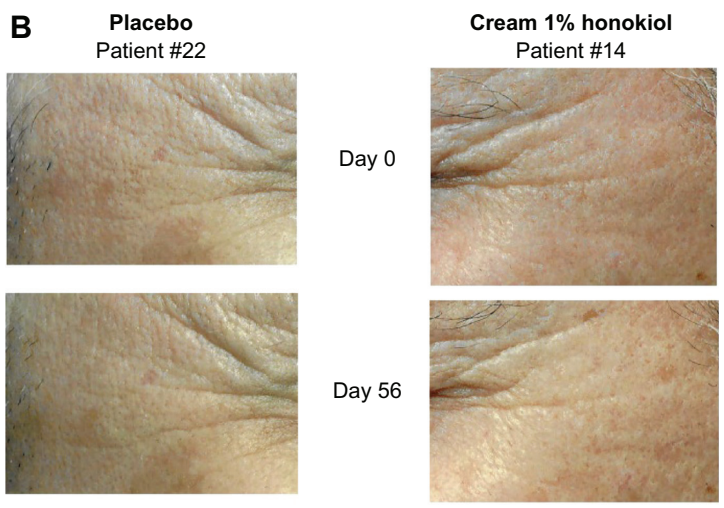

Patient \#16
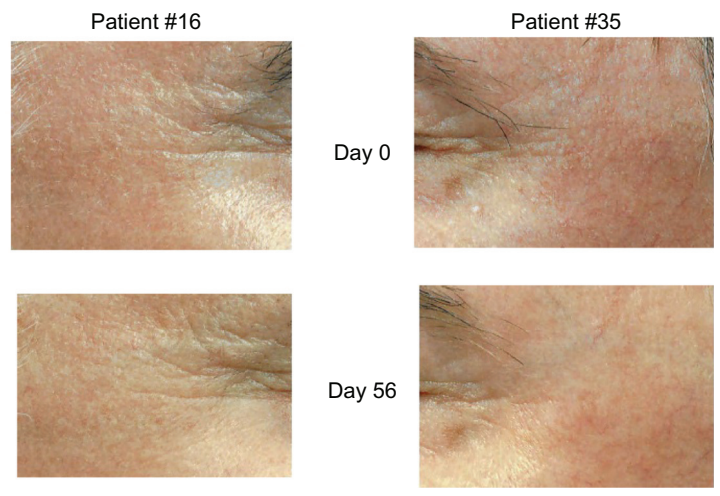

Figure 3B Antiwrinkle effect of a preparation containing I\% of honokiol, on the crow's feet of two volunteers.

Note: Comparison between study start and end (day 0 and day 56).
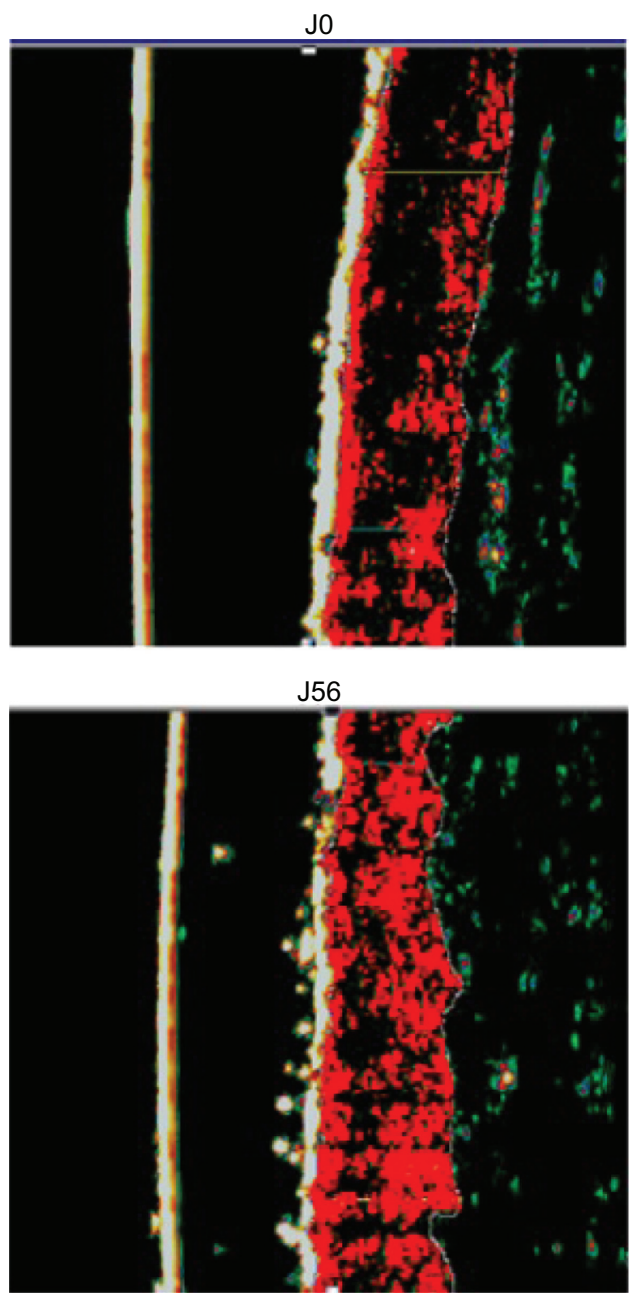

Figure 4 Dermal redensifying effect of the $1 \%$ of honokiol preparation at day 0 and day 56.

Note: The redensifying effect of the dermis and the reformation of the extracellular matrix came close to statistical significance at $P<0.05(P=0.058)$. Abbreviation: $\mathrm{P}$, probability level.

of senescence by serum hormone level substitution in older individuals are still controversially discussed in the literature. ${ }^{50}$ The skin is a peripheral endocrine organ; in aging males, androgen deficiency occurs, leading to degeneration of skin and internal organs. Age-dependent decrease in tissue androgens in some skin areas was reported even a decade earlier. ${ }^{51}$ Hence, topical or even oral hormone substitution treatments were proposed to counteract defects of the skin due to decreasing hormone levels. ${ }^{1,51,52}$ Older skin shows a lower content of lipids, and further experimental work showed diminished surface permeation of certain hormones and drugs. ${ }^{52}$

Testosterone insufficiency in aging men includes negative effects on the skin and hair. The dermatologic benefits and risks of testosterone replacement therapy have to be studied in short term and long term trials. ${ }^{53}$ In a review about male aging, testosterone substitution was positively evaluated because short 
term adverse effects were not found; but in the same paper, the authors warned of possible unknown long term risks of testosterone. ${ }^{54}$ More supportive records come from another study where human skin improvements like epidermal thickness, humidity, or pigmentation were clinically observed under oral adrenal steroid treatments in both sexes. ${ }^{55}$ In stark contrast, certain risks of hormone replacement therapy were found to be statistically higher in a meta-analysis of published clinical trials, and patient monitoring was recommended. ${ }^{56}$ Over 40 years ago, the effects of testosterone injections on the aging male skin were tested, and skin improvements manifested histologically. ${ }^{57}$ In 2007 and 2010, the intracrine or paracrine actions of sex hormones produced in the skin were reviewed. The paper reports that the androgen receptor densities may have important implications in the development of hyperandrogenism and its associated skin diseases such as acne, seborrhea, hirsutism, and androgenic alopecia. ${ }^{58}$ Androgen delivery to the aging skin was registered as an invention in $2006 .{ }^{59}$ On a biochemical molecular level, testosterone was found to modulate the phospholipase A2 system in the epidermal tissue of rats. ${ }^{60}$ In addition, molecular aspects of hair and skin physiology were reviewed, and androgenic steroids, their converting enzymes, as well as certain proteins further downstream that bind their active metabolites. ${ }^{61}$

\section{Conclusion}

Our combined theoretical and experimental study extends the hitherto known literature about dermopharmaceutical antiaging treatment for male skin. Its design and technical dimensions show preliminary character, but yields sufficient evidence to direct our ongoing research and development with the following implications: honokiol inhibits aromatase and $5 \alpha$-reductase type 1 in a dose-dependent manner, with an $\mathrm{IC}_{50}$ of about $50 \mu \mathrm{M}$ and $75 \mu \mathrm{M}$, respectively. These results validate the predictions made by Selnergy. Moreover, a preliminary clinical study demonstrated that the in vivo efficacy of a testosterone-like compound, such as honokiol, is able to improve the skin aging parameters in men. The topic administration prevents the muscle-relaxing effects of honokiol that are associated with the oral administration of this compound. The ascribed antioxidative properties may play a stabilizing role in dermopharmaceutical formulations.

Additional studies are needed to test the link between testosterone pathway modulation and antiaging. Honokiol seems to be a good starting point. Moreover, honokiol is a selective inhibitor of $5 \alpha$-reductase type 1 . To our best knowledge, the number of selective $5 \alpha$-reductase type 1 (vs type 2 ) inhibitors is sparse. Therefore, honokiol is an interesting lead for further iterative cycles of drug development (design, synthesis, and bioassays) to find and test more potent and selective derivatives through hemisynthesis. Chemical optimization is necessary in order to obtain nanomolar range inhibitors of $5 \alpha$-reductase type 1 , but the optimization should also lead to compounds with no activity on $5 \alpha$-reductase type 2 .

\section{Acknowledgment}

We thank Mr Didier Rase, Paris, France for his financial support in this program.

\section{Disclosure}

The authors report no conflict of interest in this work.

\section{References}

1. Phillips TJ, Demircay Z, Sahu M. Hormonal effects on skin aging. Clin Geriatr Med. 2001;17(4):661-672.

2. Wespes E, Schulman CC. Male andropause: myth, reality, and treatment. Int J Impot Res. 2002;14 Suppl 1:S93-S98.

3. Zouboulis CC. Intrinsic skin aging. A critical appraisal of the role of hormones. Hautarzt. 2003;54(9):825-832.

4. Theodoraki A, Bouloux PM. Testosterone therapy in men. Menopause Int. 2009;15(2):87-92.

5. Beg S, Al-Khoury L, Cunningham GR. Testosterone replacement in men. Curr Opin Endocrinol Diabetes Obes. 2008;15(4):364-370.

6. Diver MJ. Laboratory measurement of testosterone. Front Horm Res. 2009;37:21-31.

7. Yeap BB. Testosterone and ill-health in aging men. Nat Clin Pract Endocrinol Metab. 2009;5(2):113-121.

8. Riggs BL, Khosla S, Melton LJ 3rd. Sex steroids and the construction and conservation of the adult skeleton. Endocr Rev. 2002;23(3):279-302.

9. Cilotti A, Falchetti A. Male osteoporosis and androgenic therapy: from testosterone to SARMs. Clin Cases Miner Bone Metab. 2009;6(3): 229-233.

10. Abdullah F, Rashid RM. Alopecia: botanical approaches in review. J Drugs Dermatol. 2010;9(5):537-541.

11. Shapiro J, Price VH. Hair regrowth. Therapeutic agents. Dermatol Clin. 1998;16(2):341-356.

12. Lee WJ, Jung HD, Chi SG, et al. Effect of dihydrotestosterone on the upregulation of inflammatory cytokines in cultured sebocytes. Arch Dermatol Res. 2010;302(6):429-433.

13. Zouboulis CC. Acne and sebaceous gland function. Clin Dermatol. 2004;22(5):360-366.

14. Larsen PR, Williams RL, editors. Williams Textbook of Endocrinology. Philadelphia: WB Saunders; 2003.

15. Sator PG, Schmidt JB, Sator MO, Huber JC, Hönigsmann H. The influence of hormone replacement therapy on skin ageing: a pilot study. Maturitas. 2001;39(1):43-55.

16. Lawrentschuk N, Fleshner N. Severe irritant contact dermatitis causing skin ulceration secondary to a testosterone patch. Scientific World Journal. 2009;20:333-338.

17. Inui S, Itami S. Molecular basis of androgenetic alopecia: From androgen to paracrine mediators through dermal papilla. J Dermatol Sci. 2011;61(1):1-6.

18. Bader U, Trüeb RM. Androgenetic alopecia in the man. Ther Umsch. 2002;59(5):211-216.

19. Trüeb RM. Molecular mechanisms of androgenetic alopecia. Exp Gerontol. 2002;37(8-9):981-990.

20. Hoffmann R. Hormonal interaction and hair growth. Ann Dermatol Venereol. 2002;129(5 Pt 2):787-792.

21. Lo YC, Teng CM, Chen CF, Chen CC, Hong CY. Magnolol and honokiol isolated from Magnolia officinalis protect rat heart mitochondria against lipid peroxidation. Biochem Pharmacol. 1994;47(3):549-553. 
22. Maruyama Y, Kuribara H. Overview of the pharmacological features of honokiol. CNS Drug Rev. 2000;6(1):35-44.

23. Liou KT, Shen YC, Chen CF, Tsao CM, Tsai SK. The anti-inflammatory effect of honokiol on neutrophils: mechanisms in the inhibition of reactive oxygen species production. Eur J Pharmacol. 2003;475(1-3):19-27.

24. Bai X, Cerimele F, Ushio-Fukai M, et al. Honokiol, a small molecular weight natural product, inhibits angiogenesis in vitro and tumor growth in vivo. J Biol Chem. 2003;278(37):35501-35507.

25. Ahn KS, Sethi G, Shishodia S, Sung B, Arbiser JL, Aggarwal BB. Honokiol potentiates apoptosis, suppresses osteoclastogenesis, and inhibits invasion through modulation of nuclear factor-kappaB activation pathway. Mol Cancer Res. 2006;4(9):621-633.

26. Lee B, Kim CH, Moon SK. Honokiol causes the p21WAF1-mediated G(1)-phase arrest of the cell cycle through inducing p38 mitogen activated protein kinase in vascular smooth muscle cells. FEBS Lett. 2006;580(22):5177-5184.

27. Battle TE, Arbiser J, Frank DA. The natural product honokiol induces caspase-dependent apoptosis in B-cell chronic lymphocytic leukemia (B-CLL) cells. Blood. 2005;106(2):690-697.

28. Hahm ER, Singh SV. Honokiol causes G0-G1 phase cell cycle arrest in human prostate cancer cells in association with suppression of retinoblastoma protein level/phosphorylation and inhibition of E2F1 transcriptional activity. Mol Cancer Ther. 2007;6(10):2686-2695.

29. Bruneton J. Pharmacognosie, Phytochimie, Plantes Médicinales. Paris, France: Lavoisier; 1993: viii.

30. Do QT, Bernard P. Pharmacognosy and reverse pharmacognosy: a new concept for accelerating natural drug discovery. IDrugs. 2004 7(11):1017-1027.

31. Harrigan GG, Brackett DJ, Boros LG. Medicinal chemistry, metabolic profiling and drug target discovery: a role for metabolic profiling in reverse pharmacology and chemical genetics. Mini Rev Med Chem. 2005;5(1):13-20.

32. Scior T, Bernard P, Medina-Franco JL, Maggiora GM. Large compound databases for structure-activity relationships studies in drug discovery. Mini Rev Med Chem. 2007;7(8):851-860.

33. Bernard P, Scior T, Didier B, Hibert M, Berthon JY. Ethnopharmacology and bioinformatic combination for leads discovery: application to phospholipase A(2) inhibitors. Phytochemistry. 2001;58(6):865-874.

34. Berman HM, Westbrook J, Feng Z, et al. The Protein Data Bank. Nucleic Acids Res. 2000;28(1):235-242.

35. Scior T, Wahab HA. Structure prediction of proteins with very low homology: A comprehensive introduction and a case study on aminopeptidase. In: Kaplan SP, editor. Drug Design Research Perspectives. New York, NY: Nova Science Publishers; 2007:675-708.

36. Grishkovskaya I, Avvakumov GV, Sklenar G, Dales D, Hammond GL, MullerYA. Crystal structure of human sex hormone-binding globulin: steroid transport by a laminin G-like domain. EMBO J. 2000;19(4):504-512.

37. Ghosh D, Griswold J, Erman M, Pangborn W. Structural basis for androgen specificity and oestrogen synthesis in human aromatase. Journal Nature. 2009;457(7226):219-223.

38. Faucher F, Cantin L, Luu-The V, Labrie F, Breton R. Crystal structures of human Delta4-3-ketosteroid 5beta-reductase (AKR1D1) reveal the presence of an alternative binding site responsible for substrate inhibition. Biochemistry. 2008;47(51):13537-13546.

39. SYBYL, Tripos Inc. 1699 South Hanley Road, St Louis, MO, 63144, USA.

40. SciorT, Bender A, Tresadern G, et al. Recognizing pitfalls in virtual screening: a critical review. J Chem Inf Model. April 6, 2012. [Epub ahead of print.]

Clinical Interventions in Aging

\section{Publish your work in this journal}

Clinical Interventions in Aging is an international, peer-reviewed journal focusing on evidence-based reports on the value or lack thereof of treatments intended to prevent or delay the onset of maladaptive correlates of aging in human beings. This journal is indexed on PubMed Central, MedLine, the American Chemical Society's 'Chemical Abstracts Ser-
41. Purba HS, Bhatnagar AS. A comparison of methods measuring aromatase activity in human placenta and rat ovary. J Enzyme Inhib. 1990;4(2):169-178.

42. Reichert W, Hartmann RW, Jose J. Stable expression of the human 5alpha-reductase isoenzymes type I and type II in HEK293 cells to identify dual and selective inhibitors. J Enzyme Inhib. 2001;16(1):47-53.

43. Délos S, Iehlé C, Martin PM, Raynaud JP. Inhibition of the activity of 'basic' 5 alpha-reductase (type 1) detected in DU 145 cells and expressed in insect cells. J Steroid Biochem Mol Biol. 1994;48(4):347-352.

44. Boudon C, Lobaccaro JM, Lumbroso S, et al. 5 alpha-reductase activity in cultured epithelial and stromal cells from normal and hyperplastic human prostates - effect of finasteride (Proscar), a 5 alpha-reductase inhibitor. Cell Mol Biol (Noisy-le-grand). 1995;41(8):1007-1015.

45. Lowry OH, Rosebrough NJ, Farr AL, Randall RJ. Protein measurement with the Folin phenol reagent. J Biol Chem. 1951;193(1):265-275.

46. Kanehisa M, Goto S, Furumichi M, Tanabe M, Hirakawa M. KEGG for representation and analysis of molecular networks involving diseases and drugs. Nucleic Acids Res. 2010;38(Database issue):D355-D360.

47. Seralini G, Moslemi S. Aromatase inhibitors: past, present and future. Mol Cell Endocrinol. 2001;178(1-2):117-131.

48. Occhiato EG, Guarna A, Danza G, Serio M. Selective non-steroidal inhibitors of 5 alpha-reductase type 1. J Steroid Biochem Mol Biol. 2004;88(1):1-16.

49. Kahn SM, Hryb DJ, Nakhla AM, Romas NA, Rosner W. Sex hormonebinding globulin is synthesized in target cells. J Endocrinol. 2002; 175(1):113-120.

50. Makrantonaki E, Schoenknecht P, Hossini AM, et al. Skin and brain age together: The role of hormones in the ageing process. Exp Gerontol. 2010;45(10):801-813

51. Bolognia JL. Aging skin. Am J Med. 1995;98(1A):99S-103S.

52. Roskos KV, Maibach HI, Guy RH. The effect of aging on percutaneous absorption in man. J Pharmacokinet Biopharm. 1989;17(6):617-630.

53. Schreiber G, Ziemer M. The aging male-diagnosis and therapy of lateonset hypogonadism. J Dtsch Dermatol Ges. 2008;6(4):273-279.

54. MatsumotoAM. Physical, metabolic and endocrine correlates of male aging. Filicori M, editor. Endocrine Basis of Reproductive Function, Proceedings of the Conference; January 20-22, 2000; Tampa, FL, US: 525-535.

55. Baulieu EE, Thomas G, Legrain S, et al. Dehydroepiandrosterone (DHEA), DHEA sulfate, and aging: contribution of the DHEAge Study to a sociobiomedical issue. Proc Natl Acad Sci U S A. 2000;97(8):4279-4284.

56. Calof OM, Singh AB, Lee ML, et al. Adverse events associated with testosterone replacement in middle-aged and older men: a meta-analysis of randomized, placebo-controlled trials. J Gerontol A Biol Med Sci. 2005;60(11):1451-1457.

57. Wright ET, McGillis TJ, Sobel H. Action of testosterone on the skin of aging male subjects. Dermatologica. 1970;140(2):124-128.

58. Zouboulis CC, Chen WC, Thornton MJ, Qin K, Rosenfield R. Sexual hormones in human skin. Horm Metab Res. 2007;39(2):85-95.

59. El-Alfy M, Labrie F, Azzi L, inventors; Endorech Inc, assignee. Use of androgens to reduce the likelihood of acquiring or to treat skin aging. United States patent US 2006/0178352 A1. November 1, 2005.

60. Sergeev PV, Ukhina TV, Shimanovskii NL. Effects of hormones on phospholipase A2 activity in rat skin. Pharmacology and Toxicology. 2000;129(1):60-62.

61. Ebling FJ. Hair. J Invest Dermatol. 1976;67(1):98-105.

vice' (CAS), Scopus and the Elsevier Bibliographic databases. The manuscript management system is completely online and includes a very quick and fair peer-review system, which is all easy to use. Visit http://www.dovepress.com/testimonials.php to read real quotes from published authors. 